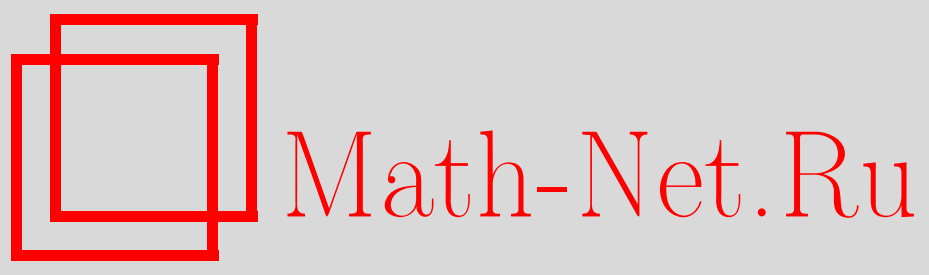

О. В. Бесов, С. В. Бочкарев, Е. А. Волков, В. А. Ильин, Б. С. Кашин, В. В. Козлов, С. В. Конягин, Н. Н. Кудрявцев, Ю. С. Осипов, С. И. Похожаев, В. А. Садовничий, А. Г. Сергеев, С. А. Теляковский, Его математический век (памяти Сергея Михайловича Никольского), УМH, 2013, том 68, выпуск 3, 205-207

DOI: https://doi.org/10.4213/rm9532

Использование Общероссийского математического портала Math-Net.Ru подразумевает, что вы прочитали и согласны с пользовательским соглашением http://www . mathnet.ru/rus/agreement

Параметры загрузки:

IP: 54.84 .234 .179

26 апреля 2023 г., 17:21:24

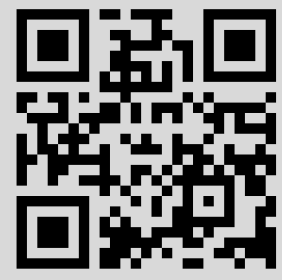




\section{Его математический век (памяти Сергея Михайловича Никольского)}

9 ноября 2012 г. на 108-м году ушел из жизни выдающийся русский математик, ученый, педагог и организатор науки, академик Российской академии наук Сергей Михайлович Никольский.

Сергей Михайлович прожил долгую и достойную жизнь. Он родился 30 апреля 1905 г. в Заводе Талица Пермской губернии (ныне Талица Пермской области). Его отец Михаил Дмитриевич Никольский имел звание ученого лесовода первого разряда, после революции работал лесничим в Воронежской губернии. Был убит бандитами в 1921 г. Мать Людмила Михайловна была сельской учительницей. Сергей, будучи подростком, начал работать в лесничестве, а затем в совхозе. После смерти отца семья Никольских перебралась в Чернигов, где Сергей Михайлович работал в Губполитпросвете и учился в Индустриально-агрономическом техникуме. В 1925 г. он поступил в Институт

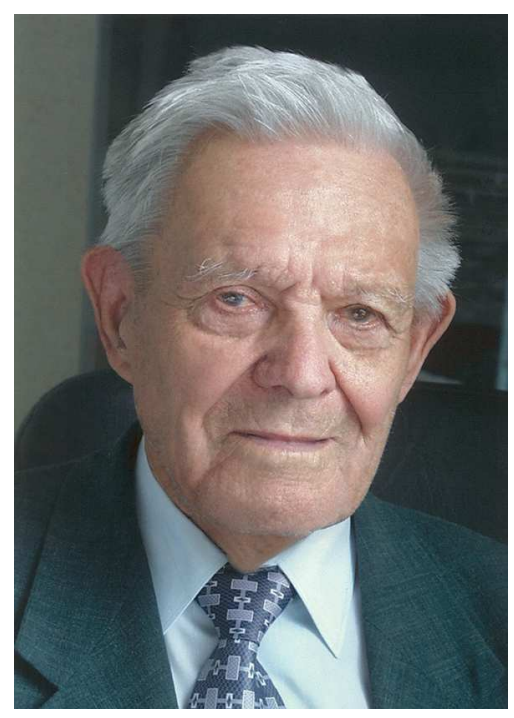
народного образования в городе Екатеринославе (Днепропетровск) и уже на первом курсе серьезно увлекся математикой. В 1929 г. С. М. Никольский был оставлен в институте преподавателем. Сергей Михайлович был постоянным слушателем лекций профессоров МГУ А.Н. Колмогорова и П. С. Александрова, регулярно приезжавших в Днепропетровск. Вскоре он - один из учеников А.Н. Колмогорова, ставшего для него не просто научным руководителем, но и наставником.

В 1934-1935 гг. С. М. Никольский был откомандирован в Московский университет для работы над кандидатской диссертацией. Он занимался, по его словам, с 9 часов утра до 9 часов вечера, посещал семинары А.Н. Колмогорова, В. Л. Гончарова, А. И. Плеснера, Л.А. Люстерника и другие. После защиты в 1935 г. кандидатской диссертации по линейным уравнениям в банаховом пространстве Сергей Михайлович возглавлял кафедру теории функций в Днепропетровском университете. Руководимый им семинар рассматривается теперь как начало создания Днепропетровской школы теории приближения функций.

С января 1941 г. Сергей Михайлович - докторант Математического института им. В. А. Стеклова. До начала войны он завершил работу над докторской диссертацией. Во время войны он почти два месяца работал на строительстве оборонительных сооружений под Малоярославцем. В октябре 1941 г. Математический институт был эвакуирован в Казань, где в январе 1942 г. Сергей Михайлович защитил докторскую диссертацию по теории приближения функций.

С 1941 г. научная жизнь Сергея Михайловича проходила в Математическом институте в Отделе теории функций. В 1953-1961 гг. он был заместителем директора

DOI: $10.4213 / \mathrm{rm} 9532$ 
МИАН, в 1960-1988 гг. заведовал Отделом теории функций. В 1968 г. Сергей Михайлович избирается членом-корреспондентом АН СССР, а в 1972 г. - академиком.

Первые научные исследования С. М. Никольского посвящены линейным уравнениям в банаховых пространствах. Открывает этот цикл работа 1936 г., являющаяся основой кандидатской диссертации Сергея Михайловича, а завершает работа 1943 г., сыгравшая и продолжающая играть значительную роль в развитии функционального анализа и алгебры. С. М. Никольский установил, что сумму обратимого и вполне непрерывного оператора можно представить в виде суммы обратимого и конечномерного линейного оператора не только в банаховых пространствах с базисом, но и в произвольных банаховых пространствах. Приведенная теорема Никольского открыла новые направления в функциональном анализе - обобщенные фредгольмовы элементы в кольцах операторов, а также в структурной теории колец.

С. М. Никольский решил ряд трудных задач теории приближения функций. Он выяснил асимптотическое поведение верхних граней уклонений в равномерной метрике периодических функций от частных сумм их рядов Фурье, когда верхние грани берутся по классам функций с фиксированной мажорантой модуля непрерывности производной заданного порядка. Аналогичная задача была решена им также для приближения средними Фейера, интерполяционными полиномами и в ряде других случаев.

Особое место занимает работа С. М. Никольского 1946 г. о приближении в среднем, в которой рассматриваются приближения в метрике $L$. В этой работе он установил свои знаменитые теоремы двойственности о приближении в общих банаховых пространствах. Теоремы двойственности Никольского сыграли важную роль в решении ряда трудных задач теории приближения функций. Они получили значительное продолжение и развитие в функциональном анализе. Велика роль С. М. Никольского в постановке и решении прямых и обратных задач о приближении функций алгебраическими многочленами.

С. М. Никольским создана теория наилучших квадратурных формул на классах функций одной переменной. Его монография "Квадратурные формулы" (1958) неоднократно переиздавалась. Она стимулировала дальнейшее изучение экстремальных задач для квадратурных формул и содействовала внедрению результатов теоретических исследований в практику вычислений.

В последние годы С. М. Никольский активно разрабатывал новое направление в теории приближений функций многих переменных, изучая приближения на общих многообразиях следами целых функций экспоненциального типа и алгебраическими многочленами.

В 1951 г. С. М. Никольский опубликовал свои знаменитые неравенства разных метрик для целых функций и тригонометрических полиномов многих переменных, связывающие их $L_{p}$-нормы при разных $p$. Эти неравенства дали ему возможность связать аппроксимационные свойства функций с их гладкостью (включая гладкость нецелого порядка) и применить эти результаты к исследованию введенных им банаховых пространств дифференцируемых функций $H_{p}^{r}\left(\mathbb{R}^{n}\right)$, что открыло новое направление исследований в теории пространств дифференцируемых функций многих переменных и их приложениях к задачам математической физики.

Сергей Михайлович построил теорию вложения пространств $H_{p}^{r}\left(\mathbb{R}^{n}\right)$, установил замкнутость системы этих пространств относительно теорем вложения и обратных теорем о продолжении. Его теория охватывает как изотропные, так и неизотропные по гладкости пространства дифференцируемых функций на многообразиях различного числа измерений. Эта теория в последующие годы развивалась в трудах самого Сергея Михайловича и многих других математиков.

Полученные результаты позволили С. М. Никольскому развить общую теорию соответствующих краевых задач для эллиптических и более общих дифференциальных уравнений. 
Цикл совместных работ С. М. Никольского и П. И. Лизоркина, начатый в 1994 г., посвящен весовым пространствам дифференцируемых функций и их приложениям к вырождающимся эллиптическим уравнениям. Этот цикл содержит результаты по граничным значениям функций из весовых пространств (влияющих на постановку граничных задач), по единственности и дифференциальным свойствам решений. В дальнейшем это направление получило развитие в теории вырождающихся эллиптических уравнений произвольного порядка.

Другой цикл работ С. М. Никольского посвящен краевым задачам для эллиптического оператора с постоянными коэффициентами в случае, когда правая часть уравнения - многочлен или граничные условия Дирихле - след многочлена. Сергей Михайлович выяснил условия, при которых решение также является многочленом. Эти результаты являются существенным обобщением классического результата об операторе Лапласа и шаре. В случае произвольной правой части Сергей Михайлович находит метод решения, основанный на аппроксимации функций многочленами.

После 2005 г. С. М. Никольский активно занимался проблемами регулярности решений вариационных задач на основе прямых вариационных методов.

Выдающиеся достижения Сергея Михайловича в области математического анализа имеют широкое мировое признание. Он создал несколько научных направлений в математическом анализе, успешно развивающихся в нашей стране и за рубежом. Его научная школа получила всемирное признание.

Неоценим вклад Сергея Михайловича в математическое образование. Он несколько лет заведовал кафедрой высшей математики МФТИ, формируя стиль преподавания; более 50 лет читал основные математические курсы. Им и под его руководством написано более 20 учебников для студентов и школьников. Сергей Михайлович много работал с аспирантами и молодыми учеными, более 50 лет он руководил научным семинаром в МИАН. Среди его учеников 75 кандидатов и докторов наук, несколько членов Российской академии наук и Национальных академий наук Украины и Казахстана.

Широта научных интересов, внимание к окружающим и исключительная доброжелательность С. М. Никольского всегда привлекали к нему и молодых, и сложившихся математиков, ощущавших его заботу и поддержку.

Всю свою жизнь Сергей Михайлович занимался и научно-организационной деятельностью. С 1953 по 1961 г. он непосредственно участвовал в организации РЖ "Математика" и был его главным редактором. С 1975 по 1987 г. был ответственным редактором Трудов МИАН. Активно участвовал в организации в 1975 г. советско-венгерского журнала "Analysis Mathematica" и до конца жизни являлся главным редактором российской секции. Он являлся почетным редактором и почетным главным редактором международных математических журналов. Сергей Михайлович много внимания уделял и международной научно-организационной деятельности.

С. М. Никольский был удостоен ряда правительственных наград (в том числе 4 орденов). Он трижды лауреат Государственной премии СССР, лауреат Государственной премии Украины, двух государственных премий Правительства РФ, иностранный член четырех зарубежных академий, удостоен нескольких премий и медалей Российской и зарубежных академий наук, ряда почетных званий. Помимо научного и педагогического наследия Сергей Михайлович оставил после себя книги ярких воспоминаний о своей жизни и математической жизни страны: “Мой математический век" (2003), "Мой век" (2005) и др.

Память о выдающемся ученом и прекрасном человеке навсегда сохранится в сердцах его близких, друзей, коллег, учеников и всех тех, кому довелось с ним общаться.

О.В. Бесов, С.В. Бочкарев, Е.А. Волков, В.А. Ильин, Б.С. Кашин, В.В. Козлов, С.В. Конягин, Н.Н. Кудрявцев, Ю. С. Осипов, С.И. Похожаев, В.А. Садовничий, А.Г. Сергеев, С.А. Теляковский 